\title{
Basal and Stimulated C-fos mRNA Expression in the Rat Brain: Effect of Chronic Dietary Lithium
}

Jeannette C. Miller, Ph.D., and Aleksander A. Mathé, M.D., Ph.D.

The mechanisms underlying the therapeutic efficacy of lithium in affective disorders are poorly understood; however, previous studies have established an influence of lithium on receptor-coupled and postreceptor signal transduction mechanisms, including the transcription factor $c$-fos. We investigated the effect of chronic lithium on basal, stress-, muscarinic-, and haloperidol-induced c-fos $m R N A$ expression in various rat brain regions. Chronic lithium produced significant reductions in basal $c$-fos expression in the frontal cortex and hippocampus,

confirming our previous report. Stress-induced $c$-fos was significantly attenuated in the frontal cortex, hippocampus, and pituitary, was increased in the occipital cortex, and unchanged in the hypothalamus by chronic lithium.

Pilocarpine-induced $c$-fos was significantly reduced in the frontal cortex and hippocampus by chronic lithium, but was enhanced in the occipital cortex and hypothalamus.

Haloperidol-induced c-fos was augmented in the striatum and pituitary, but reduced in the frontal cortex by chronic

KEY WORDS: Lithium; $\mathrm{c}$-fos; Affective disorder; Cholinergic; Dopaminergic; Signal transduction; Stress; Rat brain

Lithium is effective in the treatment and long-term prophylaxis of patients with affective disorder. Although

From the Millhauser Laboratories of the Department of Psychiatry (JCM), New York University Medical Center, New York, New York, and the Department of Psychiatry (AAM), Institution of Clinical Neuroscience, Karolinska Institute, St. Gorans Hospital, Stockholm, Sweden.

Address correspondence to: Jeannette C. Miller, Ph.D., Millhauser Laboratories of the Department of Psychiatry, TN 517, 550 First Avenue, New York, New York 10016.

Received April 23, 1996; accepted November 20, 1996. lithium treatment. In regions in which haloperidol did not induce fos expression in control animals, fos levels after haloperidol were reduced after chronic lithium. One week after discontinuation of the lithium treatment, basal c-fos levels remained significantly lower in the frontal cortex and hippocampus, whereas the effects of stress, pilocarpine, or haloperidol on fos were normalized in most regions, except in the hippocampus, where the attenuated fos response to injection stress persisted. We suggest that repression of basal fos expression and inhibition and activation of inducible fos may be factors to be considered in the longerterm effects of lithium, leading to changes in expression of genes that regulate fos and are regulated by Fos, and ultimately to alterations in the functional activity of neural systems involved in the pathophysiology of affective disorder. [Neuropsychopharmacology 16:408-418, 1997] (c) 1997 American College of Neuropsychopharmacology

the neurochemical and molecular mechanisms underlying the mood-stabilizing effects of lithium are unknown, lithium's acute actions, to reduce signaling through the phosphoinositol-protein kinase C (PI/PKC), and CAMP-protein kinase $\mathrm{A}$ (PKA) second-messenger systems are well documented (Manji and Lenox 1994; Manji et al. 1995 for reviews). These actions of lithium on second-messenger signaling suggest that further downstream effects may also be significant in lithium's mood-stabilizing effects. A common effector of signaling through the PI/PKC and CAMP/PKA pathways is the proto-oncogene $c$-fos. The fos and jun genes are members of a group of genes, the immediate early genes 
(IEGs), that encode nuclear phosphoproteins known to play a role in cellular differentiation (Angel and Karin 1991). IEGs also are induced in the central nervous system (CNS) in response to a variety of extracellular stimuli, including neurotransmitters, growth factors, and stress (Sheng and Greenberg 1990; Morgan and Curran 1991). Members of the Fos and Jun family of proteins are believed to play a prominent role in the long-term changes in neuronal function in response to these stimuli by altering the expression of genes containing activator protein-1 (AP-1) sequences that bind Fos:Jun heterodimeric or Jun:Jun homodimeric complexes (Franza et al. 1988; Rauscher et al. 1988).

A possible influence of lithium on fos expression was first indicated in a study by Kalasapudi et al. (1990) who showed that fos expression was induced in PC12 cells by acute lithium. In that study, it also was demonstrated that lithium enhanced fos expression induced by protein kinase $\mathrm{C}$ (PKC)-linked muscarinic cholinergic agonist stimulation. In other studies in PC12 cells, Divish et al. (1991) provided evidence that lithium enhanced fos expression through receptors and postreceptor activators of PKC, but not through receptor activators of the cAMP pathway. Subsequently, Weiner et al. (1991) extended the findings in PC12 cells to the rat cortex, where it was shown that acute lithium pretreatment enhanced pilocarpine-induced fos, whereas subchronic (6-day) lithium treatment also augmented the fos response but less than after acute lithium exposure.

An important criterion for defining a mechanism for the therapeutic action of lithium or for any psychotropic drug requires investigating the drug's biological effects in a time frame relevant to its clinical action in humans. Only recently have there been reports utilizing chronic treatment paradigms to study the effects of lithium on signal transduction processes involving alteration of transcription factor gene expression. Williams and Jope (1994) found small increases in cortical and hippocampal c-fos and junB in animals given a low subconvulsant dose of pilocarpine. After chronic lithium treatment, the fos response to this low dose of pilocarpine was unchanged in the cortex but reduced in the hippocampus; however, a 6-fold higher pilocarpine dose, which produced seizure activity in combination with the lithium, enhanced c-fos expression in the cortex (Williams and Jope 1994).

In a previous report, we presented evidence that the basal expression of c-fos was significantly reduced in cortical, hippocampal, and hypothalamic brain areas of rats fed dietary lithium for 4 weeks (Mathé et al. 1995). To investigate further the effect of chronic lithium treatment on brain fos expression, we examined fos mRNA induction in various rat brain regions after cholinergic stimulation with a subconvulsant dose of pilocarpine and also after treatment with a therapeutic dose of the dopamine $(\mathrm{DA}), \mathrm{D}_{2}$ receptor antagonist, haloperidol.
The interest in the DAergic system stems from studies suggesting that DA plays a role in the therapeutic effects of lithium (Gottberg et al. 1988; Diehl and Gershon 1992; Baptista et al. 1993; Carli et al. 1994) and observations that some neuroleptic drugs $\left(\mathrm{D}_{2}\right.$ antagonists) useful in the treatment of mania (Kane 1988) induce fos and Fos protein in the striatum and nucleus accumbens of the rat brain (Dragunow et al. 1990; Miller 1990; Robertson and Fibiger 1992).

\section{METHODS}

\section{Drugs}

Haloperidol hydrochloride and pilocarpine hydrochloride were from Sigma (St. Louis, MO). Haloperidol was solubilized in dilute lactic acid ( $\mathrm{pH} 4.5$ ) and brought to a concentration of $5 \mathrm{mg} / \mathrm{ml}$ with normal saline (final $\mathrm{pH}$ 5.5). Pilocarpine was dissolved in normal saline $(\mathrm{pH}$ 6) to a concentration of $5 \mathrm{mg} / \mathrm{ml}$. Vehicle solutions, prepared as a control for haloperidol or for pilocarpine, were $\mathrm{pH}$-matched and identical volumes were administered as the drug solutions. The haloperidol dose (1 $\mathrm{mg} / \mathrm{kg}$ ) was chosen on the basis of clinical equivalence to an average dose of $15 \mathrm{mg} /$ day in humans (Seeman et al. 1976), its fairly selective action for DA, $D_{2}$ receptors at this dose (Meltzer et al. 1989), and the ability to induce fos mRNA in some brain regions in rodents (Miller 1990). The low pilocarpine dose $(5 \mathrm{mg} / \mathrm{kg}$ ) was chosen to minimize the possibility of seizure activity, which can occur in animals receiving lithium and because this dose has previously been used in studies of the effects of lithium on cholinergic stimulated fos responses in the brain (Weiner et al. 1991; Williams and Jope 1994).

\section{Chronic Lithium Treatment}

Male Sprague-Dawley rats, initially 35 to 37 days of age, were obtained from ALAB (Solna, Sweden). The animals were kept in standard temperature and light conditions $\left(21 \pm 1^{\circ} \mathrm{C}\right)$ with a 12-hour light-dark cycle, in accordance with the Karolinska Institute's Guidelines for Animal Care and were allowed 7 to 8 days to accommodate to their new environment prior to initiating the lithium treatment at 6 weeks of age. The rats, housed 5 per cage, had free access to water, standard rat food, or lithium supplemented in the rat chow. The amount of lithium-supplemented diet consumed by individual animals could not be determined with these housing conditions; however the amount of food consumed by rats receiving the lithium diet or the normal diet was monitored daily and was about the same among the cages. Along with regular tap water, all lithium-exposed animals had free access to a bottle containing $0.9 \% \mathrm{NaCl}$ to prevent lithium toxicity (Ellis and Lenox 1990). We have previously shown in other inves- 
tigations using an identical lithium dose but shortened time ( 4 weeks) that the mean serum lithium concentration ranged from 0.4 to $0.9 \mathrm{mEq} / \mathrm{l}$ (Mathé et al., unpublished data). In one recent study it was $0.53 \pm 0.15$ $\mathrm{mEq} / \mathrm{l}$ (Mathé et al. 1994) for the rats fed lithium. These serum lithium levels are within the range of therapeutic maintenance dose levels $(0.4$ to $0.8 \mathrm{mM} / \mathrm{l})$ in humans (Gelenberg et al. 1989).

One group of animals $(n=15)$ received normal laboratory rat chow for 7 weeks, and a second group $(n=30)$ received identical amounts of rat chow to which lithium sulfate (Astra AB, Sodertalje) in a dose of $2.19 \mathrm{~g} / \mathrm{kg}$ was admixed. At the end of the 6 weeks, a subgroup of lithium-treated animals ( $n=15)$ was randomly selected and continued to receive the lithium diet for an additional 6 days. On the 7 th day, these rats were randomly divided into five treatment groups $(n=3$ each) and received the following: no treatment; a single IP injection of vehicle and sacrificed 30 minutes postinjection (control for haloperidol); haloperidol (1 mg/ $\mathrm{kg}$, IP) and sacrificed 30 minutes postinjection; vehicle (IP) and sacrificed 45 minutes postinjection (control for pilocarpine); pilocarpine $(5 \mathrm{mg} / \mathrm{kg}$ IP) and sacrificed 45 minutes postinjection. The remaining 15 lithium-treated rats were withdrawn from the lithium diet at the end of the sixth week and on the 7th day postlithium discontinuation were randomly selected to receive identical acute vehicle or drug treatments as described for the lithiumcontinued group. The rats receiving normal food during the 7-week period also were injected on the last experimental day with either vehicle, pilocarpine, or haloperidol, as described for the lithium groups. All drugs and vehicle solutions were administered on the same day of sacrifice. Sacrifice of all of the animals was conducted between 8:30 and 11:00 A.M. on the same day to minimize the influence of diurnal variation in basal fos expression (Grassi-Zucconi et al. 1993).

The 30-minute time point after haloperidol or corresponding vehicle injection was based on previous studies of the time course of fos induction in the striatum, prefrontal cortex, or cerebral cortex (Miller et al. 1989; Miller 1990; Bing et al. 1991). Williams and Jope (1994) previously studied the time course of pilocarpine's effect on fos in the cortex and hippocampus and found peak fos induction at 30 minutes and 1 hour, respectively. We chose a 45 -minute time point after pilocarpine as a compromise because of the multiple brain regions studied. A comparison of vehicle-treated animals 30 or 45 minutes before sacrifice to uninjected animals also served as a measure of lithium's effect on the fos response to injection stress (Gubits et al. 1989; Bing et al. 1991).

All animals were sacrificed by decapitation, the brains quickly removed, and regions dissected according to the method of Glowinski and Iversen (1966). The tissues were immediately frozen in liquid nitrogen and stored at $-80^{\circ} \mathrm{C}$ until shipment for analysis of c-fos
mRNA expression. The frontal cortex, occipital cortex, hippocampus, hypothalamus, striatum, and pituitary were selected because these areas are enriched in neurotransmitters that have in one way or another been implicated in affective disorders (norepinephrine, serotonin, dopamine, acetylcholine) and have been shown to be relevant sites for the action of lithium and because impairment in receptor:effector $G$ protein-coupled activity in these areas has been suggested to contribute to the pathophysiology of mood disorders (Bunney and Garland-Bunney 1987; Swerdlow and Koob 1987; Young et al. 1991; Manji et al. 1991a, 1991b; Calabresi et al. 1993).

The study was approved by the Ethical Committee for Animal Experiments, Karolinska Institute. In all experiments, the rats groomed normally, and no gross behavioral changes or signs of lithium toxicity were observed. No significant effects of the chronic lithium regimen were observed in the weights of each brain region (probability range, 0.67 to 0.97 ) or body weights among the dietary treatments (one-way ANOVA, $F=3.9917$, df $2,6, p=.079$ ), although the lithium and lithium-withdrawn group showed about $10 \%$ weight loss. Peripheral organ weights were not assessed in this study; however we previously observed no changes, except for urinary bladder weight, due to the lithium diet (Mathé et al. 1994, 1995).

\section{Northern Analysis of c-fos mRNA Expression}

Total RNA was prepared using the guanidinium isothiocyanate (GITC)-acid-phenol procedure of Chomcyznski and Sacchi (1987) for tissues above $150 \mathrm{mg}$ and by a GITC-LiCl precipitation procedure modified for small brain regions. Briefly, tissue ranging from 10 to $100 \mathrm{mg}$ was homogenized in $0.5 \mathrm{ml} 4 \mathrm{M}$ GITC containing $10 \mathrm{mM}$ EDTA, $50 \mathrm{mM}$ Tris- $\mathrm{HCl}(\mathrm{pH}=7.5)$, and $100 \mathrm{mM}$ of $\beta$-mercaptoethanol. Nonidet P-40 $(20 \mu \mathrm{l})$ was then added, the tissue was rehomogenized for $15 \mathrm{~s}$, and 0.5 $\mathrm{ml} 4 \mathrm{M} \mathrm{LiCl}$ added and placed at $4^{\circ} \mathrm{C}$ overnight. The homogenate was centrifuged for 30 minutes at 14,000 rpm in a microfuge, and the RNA-containing pellet was resuspended in $400 \mu l 3 \mathrm{M} \mathrm{LiCl}$, vortexed for 1 minute, then centrifuged for 20 minutes. The pellet was resuspended in a solubilizing buffer [0.05 M Tris, $\mathrm{pH}=7.5$, $0.1 \%$ SDS (sodium dodecyl sulfate), $10 \mathrm{mM}$ EDTA, and $100 \mathrm{mM} \beta$-mercaptoethanol], vortexed for 5 minutes, placed on dry ice for 1 minute, then revortexed for 10 minutes. The mixture was extracted twice with diethylpyrocarbonate (DEPC)-saturated phenol:chloroform: isoamyl alcohol [1:1:(24:1)] and once with chloroform. RNA was precipitated in $0.3 \mathrm{M}$ sodium acetate $(\mathrm{pH}=$ 5.5), pelleted, washed twice with $75 \%$ ethanol, and resuspended in DEPC-treated MilliQ-Plus water containing $0.05 \mathrm{mM}$ EDTA. RNA concentration was determined from the optical density at $260 \mathrm{nM}$. Northern analysis was performed as previously described (Miller 1990; 
Mathé et al. 1995). Prehybridization and hybridization conditions with a 1.0-kb Pst I fragment of c-fos cDNA radiolabeled with ${ }^{32} \mathrm{P}$-dCTP (Random Primer Extension System, Dupont, Boston, MA) were as previously described (Miller 1990). The specific activity of the c-fos probe ranged from $1.3-2 \times 10^{8} \mathrm{dpm} / \mu \mathrm{g}$. RNA quantity and quality for each sample was assessed by simultaneously probing samples with a random primed ${ }^{32} \mathrm{P}$ dCTP-labeled 564-bp fragment of rat cyclophilin cDNA as a control "unregulated" gene. Filters were washed to a stringency of $0.2 \times$ standard saline citrate buffer [ $1 \times$ $\mathrm{SSC}=\left(0.15 \mathrm{M} \mathrm{NaCl}, 15 \mathrm{mM} \mathrm{Na}_{3}\right.$ Citrate$\left.\left.-2 \mathrm{H}_{2} \mathrm{O}\right)\right]$ in $0.1 \%$ SDS for 1 hour at $55^{\circ} \mathrm{C}$, sealed in plastic bags, and exposed to Fuji RX film for 18 to 36 hours.

\section{Data Analysis}

The intensity of hybridization for the mRNA species was quantitated by video densitometric analysis of the autoradiograms using an Image Analysis Video System and Collage ${ }^{\mathrm{TM}}$ software for the Macintosh. The pixel intensity (minus background) for c-fos and for cyclophilin was determined for each sample. To ensure that the lithium diet and various acute treatments had no effect on the expression of cyclophilin, the cyclophilin data for each brain region were subjected to a two-factor ANOVA, GB-STAT for MS Windows, with factor-A = chronic diet treatments (normal diet, lithium diet, lithium diet + discontinuation of lithium), and factor $B=$ acute drug challenge (no treatment; vehicle, 30 minutes; haloperidol, 30 minutes; vehicle, 45 minutes; and pilocarpine, 45 minutes) as main effects (see Results). The data for fos were then corrected for quantity of RNA by calculating a fos:cyclophilin ratio for each sample and mean \pm SD for each treatment group. The fos:cyclophilin ratios determined for each region for each of the three diet treatment conditions and five acute drug or vehicle treatments outlined in the Methods were statistically evaluated using a two-factor ANOVA (factors A and $B$ above as main effects). Post hoc comparisons were made with Tukey's $t$-test.

\section{RESULTS}

\section{Effect of Chronic Lithium, Lithium Discontinuation, and the Acute Drug Treatments on Cyclophilin mRNA Expression}

The pixel intensities obtained for cyclophilin in each of the brain regions from rats receiving the various diets and acute treatments were analyzed as described in Data Analysis. Neither a significant effect of the lithium diets or acute drug or vehicle treatments or a significant interaction between the diet condition and acute treatments was observed in cyclophilin expression in any brain area.

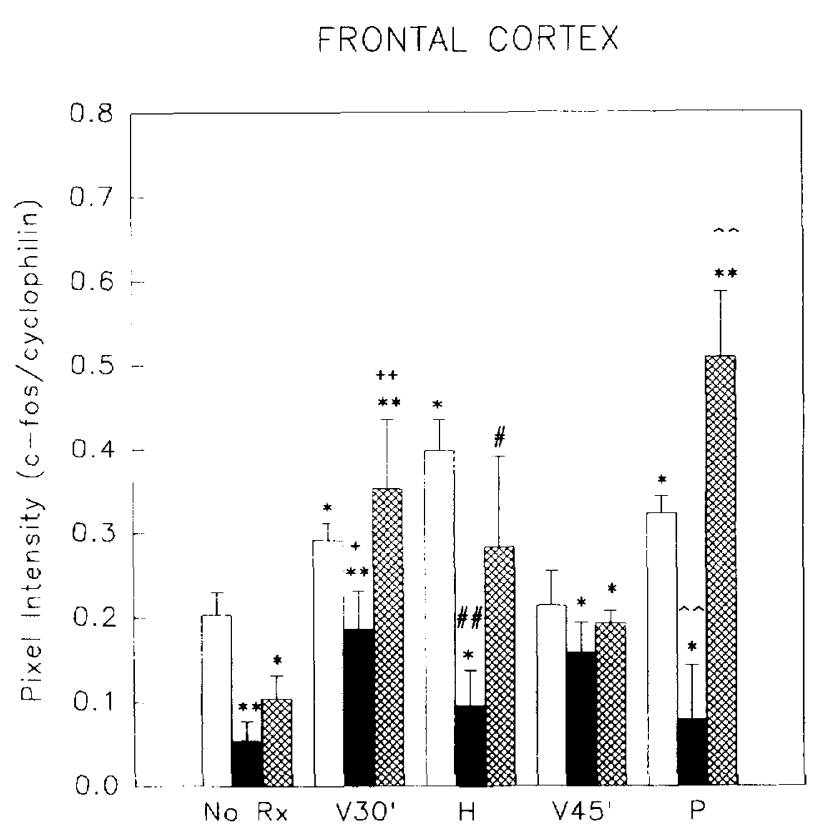

Figure 1. Relative fos/cyclopholin expression (mean \pm SD) in the frontal cortex of rats receiving 7 weeks of a normal diet, a lithium diet, or 6 weeks of a lithium diet followed by 1 week of a normal diet and various acute treatments as described in Methods. Two-factor ANOVA was used. Main effects, Factor $\mathrm{A}$ and Factor $\mathrm{B}$ are as described in Methods: (factor $\mathrm{A}, F_{2,30}=55.8564, p<.0001$; factor $\mathrm{B}, F_{4,30}=18.6105$, $\left.p<.0001 ; \mathrm{A} \times \mathrm{B}, F_{8,30}=9.4803, p<.0001\right)$. Tukey's $t$-test: lithium effects, ${ }^{*} p<.05,{ }^{* *} p<.01$ vs. normal diet; injection stress effects, ${ }^{*} p<.05,{ }^{* *} p<.01$, V30 or V45 vs. corresponding no drug diet controls, ${ }^{+} p<.05$ vs. normal diet, ${ }^{++} p<.01$ vs. lithium diet; haloperidol effects, ${ }^{*} p<.05$, vs. corresponding V30 diet controls, ${ }^{\#} p<.05,{ }^{\# \#} p<.01$ vs. normal diet after haloperidol; pilocarpine effects, ${ }^{*} p<.05,{ }^{* *} p<.01$ vs. corresponding V45 diet controls, $\wedge p<.05, \wedge \wedge p<.01$ vs. normal diet after pilocarpine. Open bars, normal diet; solid bars, lithium diet; cross-hatched bars, lithium withdrawal. Representative Northern blot is shown in Figure 7.

\section{Effect of Chronic Lithium and Lithium Discontinuation on Basal and Stress-Induced c-fos Expression}

Lithium significantly reduced basal c-fos in the frontal cortex and hippocampus (Figures 1 and 3). After discontinuation of lithium for 1 week, basal c-fos expression remained statistically lower than in control animals in these regions. As can be seen in Figures 1 to 6, animals treated with a normal diet showed a significant fos response after a single injection at 30 minutes but not at 45 minutes in all brain regions except the striatum (Figure 5). In animals fed the lithium diet, fos also was induced after vehicle injection in the frontal cortex, occipital cortex, and hypothalamus, but not in the hippocampus. After lithium was discontinued for 1 week, fos induction by vehicle injection was observed in the hippocampus as well as in the frontal cortex and hypothalamus, whereas no evidence of induction was observed in the occipital 
OCCIPITAL CORTEX

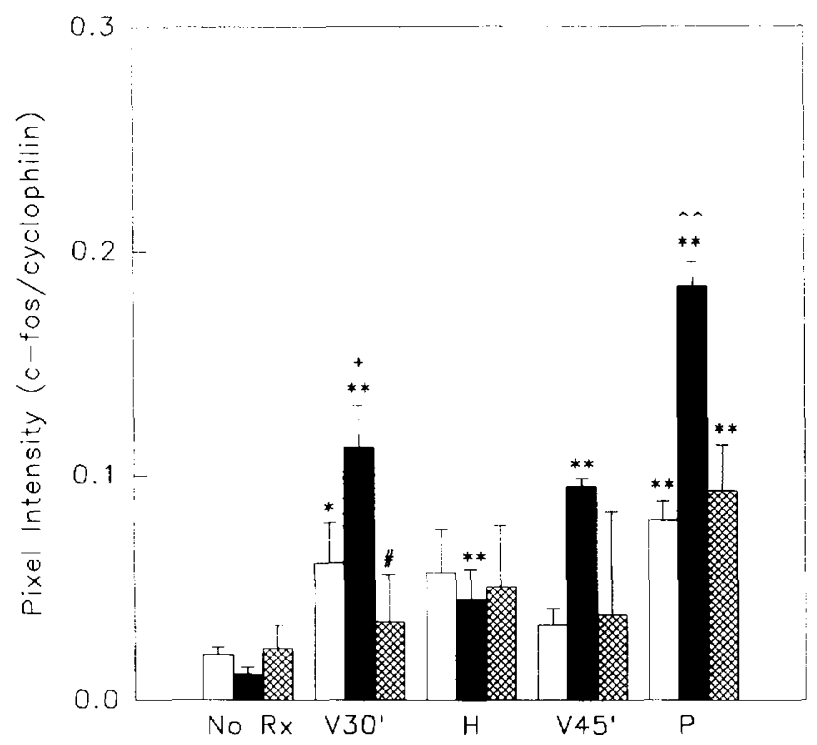

Figure 2. Relative fos/cyclophilin expression (mean \pm SD) in the occipital cortex. See legend to Figure 1. Two-factor ANOVA (factor A, $F_{2,30}=23.5043, p<.0001$; factor B, $F_{4,30}=$ $\left.34.4864, p<.0001 ; \mathrm{A} \times \mathrm{B}, F_{8,30}=7.0257, p<.0001\right)$. Tukey's $t$-test: injection stress effects, ${ }^{*} p<.05,{ }^{* *} p<.01, \mathrm{~V} 30$ or V45 vs. corresponding no drug diet controls, ${ }^{+} p<.01$ vs. normal diet, ${ }^{\#} p<.01$ vs. lithium diet; haloperidol effects, ${ }^{* *} p<.01$, vs. V30 lithium diet control; pilocarpine effects, ${ }^{* *} p<.01$ vs. corresponding V45 diet controls, $\wedge \wedge p<.01$ vs. normal and lithium withdrawal diets after pilocarpine. Open bars, normal diet; solid bars, lithium diet; cross-hatched bars, lithium withdrawal.

cortex at 30 or 45 minutes. Vehicle injection did not induce fos expression in the pituitary or striatum of the lithium-treated or lithium-discontinued groups.

In comparison to non-lithium-treated stressed controls fed the normal diet, the injection stress-induced fos response was markedly attenuated in the frontal cortex and hippocampus (Figures 1 and 3), but was augmented in the occipital cortex (Figure 2) of chronically lithium-treated rats. Stress-induced fos in the pituitary, evidenced in animals fed a normal diet, was inhibited in animals fed the lithium diet (Figure 6). Although the fos response to stress was enhanced in the hypothalamus, it was equally enhanced in rats fed a normal diet, a lithium diet, or rats discontinued from the lithium diet (Figure 4). After discontinuation of the lithium diet, the attenuation of the stress-induced fos response persisted in the hippocampus, but was no longer evident in the frontal cortex, where fos levels were no different from those seen in injected animals fed the normal diet. In the occipital cortex, the fos response 30 minutes after injection stress was now significantly lower than that seen in the lithium-treated stressed animals but was not different from the response observed in non-lithium stressed controls.

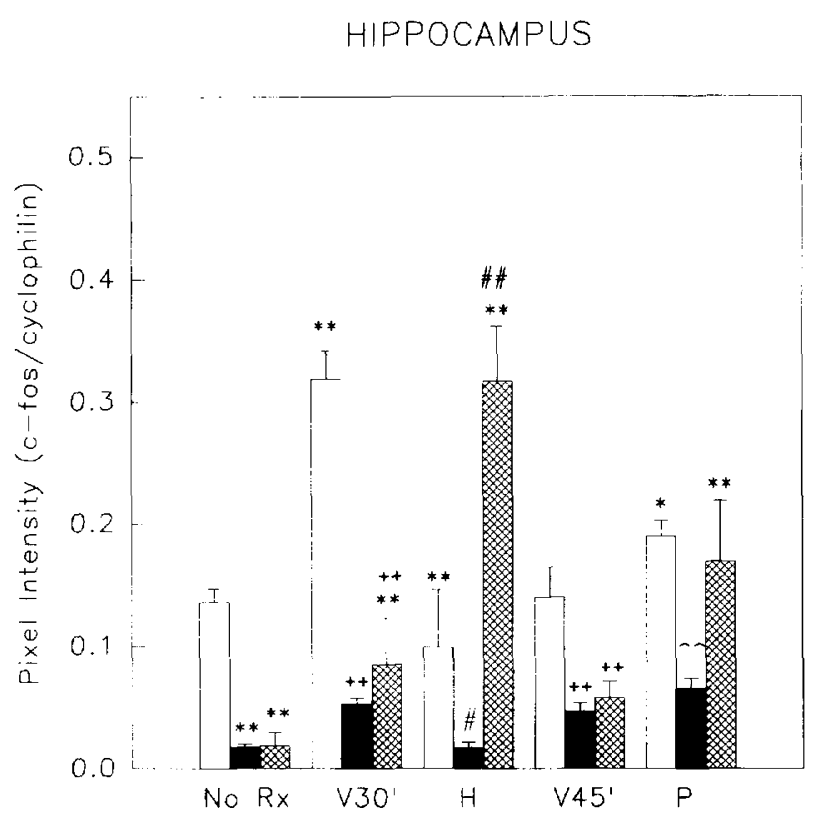

Figure 3. Relative fos/cyclophilin expression (mean \pm SD) in the hippocampus. See legend to Figure 1. Two-factor ANOVA (factor A, $F_{2,30}=107.9004, p<.0001$; factor b, $F_{4,30}=$ $\left.24.8551, p<.0001 ; \mathrm{A} \times \mathrm{B}, F_{8,30}=36.4718, p<.0001\right)$. Tukey's t-test: lithium effects, ${ }^{* *} p<.01$ vs. no drug normal diet; injection stress effects, ${ }^{* *} p<.01, \mathrm{~V} 30$ vs. corresponding no drug diets, ${ }^{++} p<.01$ V30 or V45 vs. normal diet; haloperidol effects: ${ }^{* *} p<.01$ vs. corresponding V30 diet control, ${ }^{\#} p<.05$, $\# p<.01$ vs. normal diet haloperidol; pilocarpine effects: ${ }^{*} p<.05,{ }^{* *} p<.01$ vs corresponding V45 diet controls, $\wedge \wedge p<$ .01 vs. normal diet pilocarpine. Open bars, normal diet; solid bars, lithium diet; cross-hatched bars, lithium withdrawal.

\section{Effect of Chronic Lithium and Lithium Discontinuation on Pilocarpine-Induced c-fos Expression}

In comparison to the corresponding 45-minute injection of vehicle in controls, pilocarpine significantly induced fos in the frontal cortex, occipital cortex, hippocampus, and hypothalamus of rats fed a normal diet (Figures 1 to 4). In rats fed the lithium diet, pilocarpine also significantly induced fos in the occipital cortex and hypothalamus, but did not significantly induce fos in the frontal cortex and hippocampus compared with their corresponding 45-minute vehicle-treated controls. After lithium discontinuation, induction of fos by pilocarpine was observed in the frontal cortex, occipital cortex, hippocampus, and hypothalamus, compared to their corresponding 45-minute vehicle-treated controls.

The induction of fos was significantly lower in the frontal cortex and hippocampus of chronically lithiumtreated rats (Figures 1 and 3) than in the normal diet controls receiving pilocarpine; however, after lithium discontinuation, fos induction by pilocarpine was no longer attenuated and was significantly higher than the 


\section{HYPOTHALAMUS}

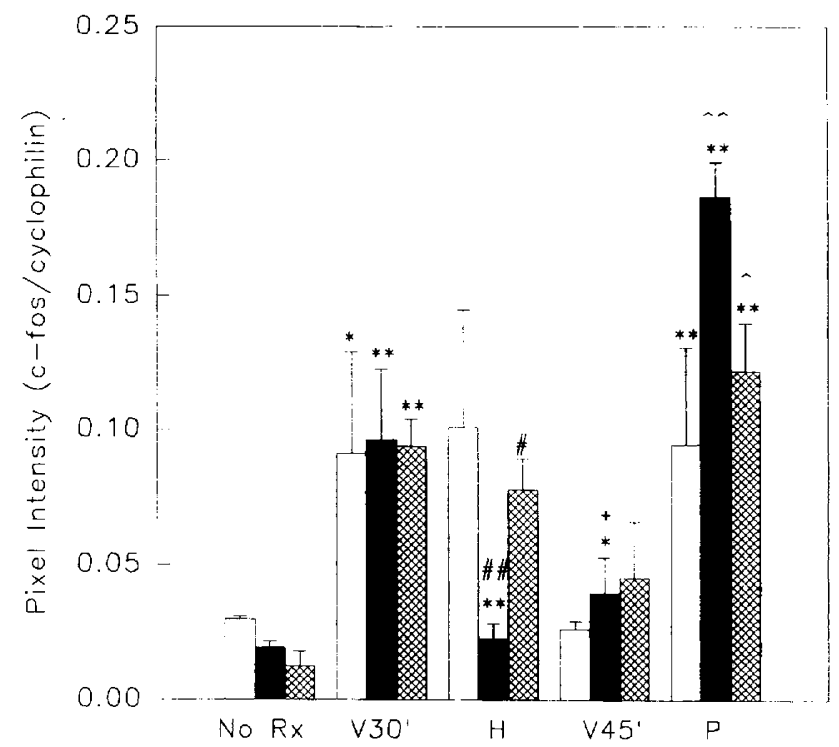

Figure 4. Relative fos/cyclophilin expression (mean \pm SD) in the hypothalamus. See legend to Figure 1 and also Figure 7. Two-factor ANOVA (factor A, $F_{2,30}=0.6970, p=.506$; factor $\mathrm{b}, F_{4,30}=22.0766, p<.0001 ; \mathrm{A} \times \mathrm{B}, F_{8,30}=4.3104, p=$ .0015). Tukey's $t$-test: injection stress effects, ${ }^{*} p<.05,{ }^{* *} p<$ .05 V30 or V45 vs. corresponding diet control, ${ }^{+} p<.05$ vs. V45 normal diet; haloperidol effects: ${ }^{* *} p<.01$ vs. corresponding V30 diet control, ${ }^{\#} p<.01$ vs. normal diet after haloperidol, ${ }^{*} p<.01$ vs. lithium diet after haloperidol; pilocarpine effects; ${ }^{* *} p<.01$ vs. responding V45 diet controls; $\wedge \wedge p<.01$ vs. normal diet pilocarpine, $\wedge p<.05$ vs. lithium diet after pilocarpine. Open bars, normal diet; solid bars, lithium diet; cross-hatched bars, lithium withdrawal.

fos levels seen after pilocarpine in animals fed the normal diet. A fos response to pilocarpine, not seen in rats fed lithium continuously, also was observed in the hippocampus of rats after lithium discontinuation; however, this response to pilocarpine was not different from that seen in the hippocampus of rats fed the normal diet. In contrast to the attenuated fos expression seen in the frontal cortex and hippocampus after chronic lithium, fos expression in response to pilocarpine was higher in the occipital cortex and hypothalamus (Figures 2 and 4 ) than in non-lithium-treated control animals receiving pilocarpine. After lithium discontinuation, these enhanced effects on fos were no longer evident. Pilocarpine had no effect on striatal or pituitary fos expression in rats fed a normal diet, a lithium diet, or in rats withdrawn from the lithium diet (Figures 5 and 6).

\section{Effect of Chronic Lithium and Lithium Discontinuation on Haloperidol-Induced c-fos Expression}

The major effects of haloperidol on c-fos were observed in the striatum and pituitary, regions containing a high

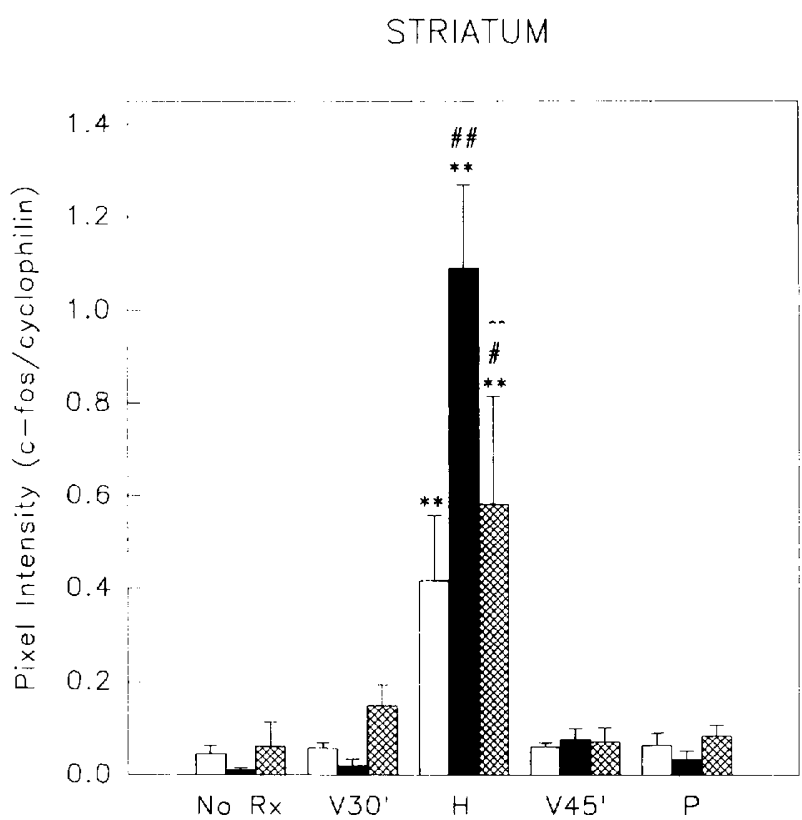

Figure 5. Relative fos/cyclophilin expression (mean $\pm \mathrm{SD}$ ) in the striatum. See legend to Fig. 1. Two-factor ANOVA (factor $\mathrm{A}, F_{2,30}=6.8893, p=.0035$; factor $\mathrm{B}, F_{4,30}=96.3213$, $\left.p<.0001 ; \mathrm{A} \times \mathrm{B}, F_{8,30}=10.9912, p<.0001\right)$. Tukey's $t$-test: haloperidol effects; ${ }^{*} p<.01$ vs. corresponding V30 diet control; ${ }^{\# \#} p<.01,{ }^{\#} p<.05$ vs. normal diet after haloperidol, $\wedge \wedge p<.01$ vs. lithium diet after haloperidol. Open bars, normal diet; solid bars, lithium diet; cross-hatched bars, lithium withdrawal.

concentration of DA, $\mathrm{D}_{2}$ receptors. Haloperidol was found to induce fos expression 7-fold in the striatum (Figure 5) in rats fed the normal diet, as previously demonstrated (Miller 1990) and 2-fold in the pituitary (Figure 6). We also observed an induction of c-fos in the striatum and pituitary of animals fed the lithium diet and in the striatum, but not in the pituitary of animals discontinued from the lithium diet for 1 week. The haloperidol-induced fos response in the animals fed the lithium diet was 2.6-fold higher in the striatum and 1.6fold higher in the pituitary than the haloperidolinduced fos response of animals fed a normal diet. After lithium discontinuation, the haloperidol-induced fos response was significantly lower in the striatum and pituitary than in animals fed the lithium diet, although the fos levels were significantly higher in the striatum, and significantly lower in the pituitary, than fos levels after haloperidol in rats fed the normal diet.

In rats receiving the normal diet, fos expression was unaltered by haloperidol in the occipital cortex or hypothalamus; however, fos expression was induced by about $36 \%$ in the frontal cortex, and fos levels in the hippocampus after haloperidol were $70 \%$ lower than in non-lithium-treated rats injected with vehicle (Figures 1 to 4). After lithium treatment and haloperidol chal- 


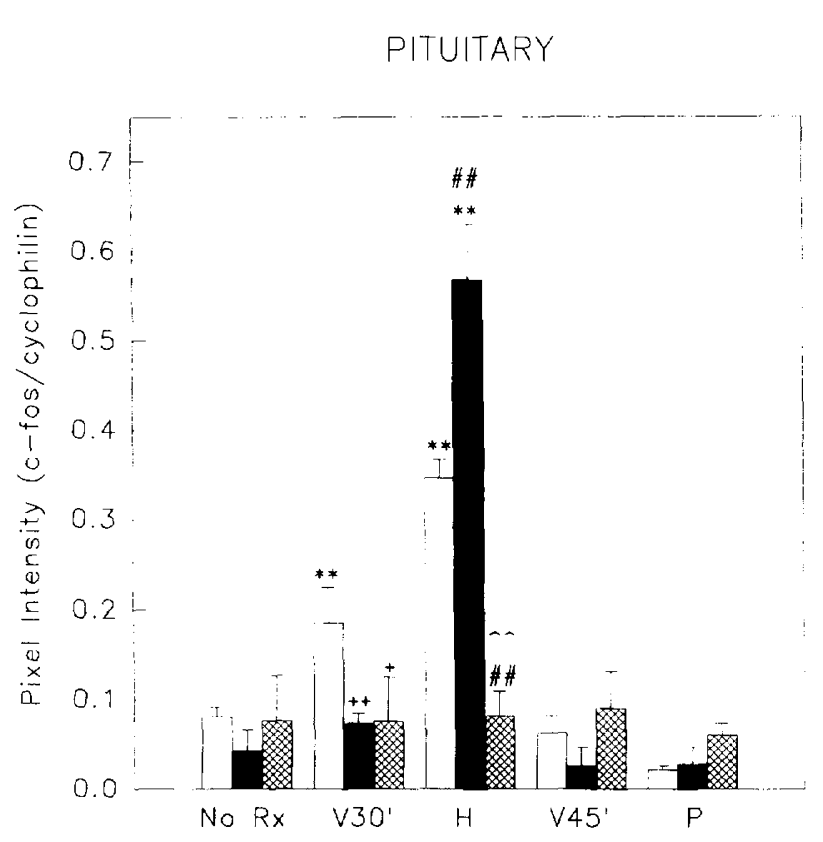

Figure 6. Relative fos/cyclophilin expression (mean \pm SD) in the pituitary. See legend to Fig. 1. Two-factor ANOVA (factor $\mathrm{A}, F_{2,30}=21.6177$; factor $\mathrm{B}, F_{4,30}=126.8263, p<.0001$; $\left.\mathrm{A} \times \mathrm{B}, F_{8,30}=41.7244, p<.0001\right)$. Tukey's $t$-test: injection stress effects; ${ }^{* *} p<.01$ V30 vs. no drug normal diet control, ${ }^{+} p<.05,{ }^{++} p<.01$ vs. V30 normal diet; haloperidol effects; ${ }^{* *} p<.01$ vs. corresponding V30 diet control; ${ }^{* \#} p<.01$ vs. normal diet after haloperidol, $\wedge \wedge p<.01 \mathrm{vs}$. lithium diet after haloperidol. Open bars, normal diet; solid bars, lithium diet; cross-hatched bars, lithium withdrawal.

lenge, fos levels in the frontal cortex, occipital cortex, and hypothalamus were lower than their corresponding 30minute vehicle controls. In comparison to rats receiving the normal diet and haloperidol, fos levels after haloperidol administration to lithium-treated rats were also significantly lower in the hippocampus, frontal cortex, and hypothalamus. This reducing effect of haloperidol on fos expression was no longer observed in these regions after discontinuation of lithium. Although haloperidol elicited a robust fos response in the hippocampus of the lithium-discontinued animals when compared with rats injected with haloperidol who were fed the normal diet or lithium continuously, the level of fos expression was not significantly different from the vehicle-injected group fed the normal diet.

\section{DISCUSSION}

In this report we confirm our previous findings of significantly diminished basal levels of $c-f o s$ in the frontal cortex and hippocampus of chronically lithium-treated rats (Mathé et al. 1995) and also show that the reduction in basal fos expression in these regions persists after discontinuation of lithium. The mechanism by which basal fos expression appears to be stably repressed by chronic lithium in the frontal cortex and hippocampus, but not in other areas examined, is not known. However, a recent study of the expression of Fos in fos-lac $Z$ transgene mice has shown that fos expression increases during neonatal brain development, declining to adult values at about 15 to 21 days postnatally, except in CA1 and CA3 neurons of the hippocampus and in some cortical neurons, where fos appears to be continuously expressed at $5 \%$ to $25 \%$ of early-development levels (Smeyne et al. 1992). These authors suggest that this low, but continuous, expression of basal fos may involve tonic activation of fos transcription or inhibition of mechanisms involved in fos repression. Chronic lithium exposure may interfere with the mechanisms underlying the sustained level of fos expression in these areas.

In addition, basal and inducible fos transcription is cell-type specific and is subject to stringent regulatory control, requiring a concerted action by a number of factors on multiple control elements directing fos promoter activity (Gilman et al. 1986; Verma and SassoneCorsi 1987; Sassone-Corsi et al. 1988; Lucibello et al. 1991). There is much evidence that chronic lithium administration impairs PI/PKC- and AC-mediated signal transduction (Hudson et al. 1993; Manji et al. 1995, for reviews), and both cellular pathways are involved in the regulation of c-fos transcription. Thus long-term lithium-induced changes in the transducing function of these two pathways may alter in a cell-specific manner any of the multiple interdependent factors regulating fos transcription, such as AP-1, serum response factor, or cAMP regulatory element binding protein (CREB); for example, CREB in its phosphorylated form is an important regulator of fos (Sassone-Corsi et al. 1988; Shaw et al. 1989; Lucibello et al. 1991). These and other factors may, in turn, also regulate multiple other genes. As yet, there are no reports of effects of lithium on nuclear factors regulating fos. Other factors, such as changes in the stability of fos mRNA or Fos protein, also may be important and need to be considered.

We also present evidence that chronic lithium administration has profound effects on the fos response to stress, muscarinic cholinergic stimulation, or DA, $\mathrm{D}_{2}$ receptor antagonism. The induction of fos by various types of stress is well established (Gubits et al. 1990; Bing et al. 1991; Schreiber et al. 1991; Titze-de-Almeida et al. 1994). In the regions where fos was induced by injection stress, an identical rapid and transient temporal course was observed, irrespective of dietary treatment. This finding suggests that the temporal course for fos induction by injection stress is not affected by chronic lithium treatment. The changes observed in stress-induced activation of $f o s$ in the frontal cortex, hippocampus, and occipital cortex may reflect postreceptor modifications in $G$ protein function and the PI/PKC and AC/PKA second-messenger systems reported to occur with chronic 


\section{Frontal Cortex}
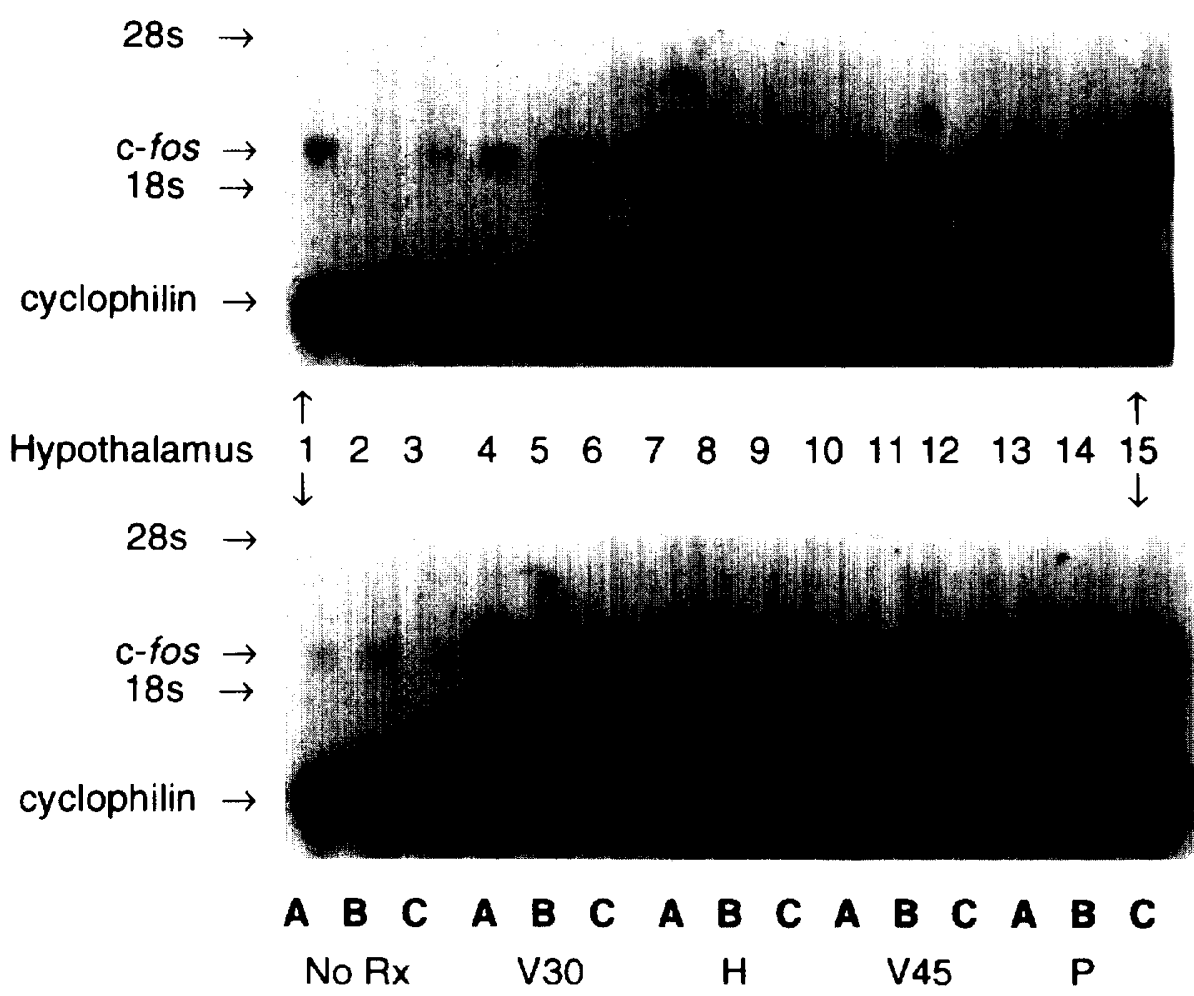

Figure 7. Northern blots of c-fos and cyclophilin mRNA expression in the frontal cortex and hypothalamus of rats receiving normal diet $(A)$; lithium diet $(B)$; and lithium diet + withdrawal $(C)$. Vehicle and drug effects: No drug (lanes 1, 2, 3); V30 (lanes 4, 5, 6); H, haloperidol (lanes 7, 8, 9); V45 (lanes 10, 11, 12); P, pilocarpine (lanes 13, $14,15)$. lithium administration (Manji and Lenox 1994; Manjii et al. 1995 for reviews). It is notable that after discontinuation of lithium, fos induction by injection stress was still significantly attenuated only in the hippocampus. This selective effect on stress-induced changes in hippocampal fos may reflect an important, stable adaptive change in neural activity associated with hippocampal function. From our limited data, it is not possible to assess the role of the multiple receptor systems mediating stress responses in the changes in fos elicited by chronic lithium treatment. However, the biogenic amine systems have been implicated in one way or another in stress responses and a variety of antidepressant treatments (Duman et al. 1994 for review), as well as in the action of lithium (Manji et al. 1995 for review). The effectiveness of lithium as an antidepressant has been questioned, but it is of interest to note that the attenuation of fos induction by acute stress seen in the frontal cortex of chronically lithium-treated animals also is seen in the frontal cortex of animals chronically administered electroconvulsive shock treatment (ECT) or several different classes of antidepressant drugs (Winston et al. 1990; Morinobu et al. 1995). These observations may offer some insight into the ability of lithium to treat both the manic and depressive aspects of bipolar disorder.

Previous studies have suggested that reduced muscarinic cholinergic neurotransmission is a factor in mania, prompting the hypothesis that lithium may produce its antimanic activity by enhancing cholinergic neurotrans- mission (Janowsky et al. 1980; Dilsaver 1986). Although there is evidence that enhancement of muscarinic stimulated fos in cell culture and in the cortex occurs acutely (Divish et al. 1991; Weiner et al. 1991), we now provide evidence that chronic lithium treatment has a differential, regional effect on muscarinic stimulated fos expression. Our observations of attenuation of pilocarpineinduced fos expression in the frontal cortex and hippocampus are in sharp contrast to those of a previous report showing enhanced fos induction in the hippocampus and cerebral cortex in chronically lithium-treated animals after $5 \mathrm{mg} / \mathrm{kg}$ pilocarpine as compared to controls (Williams and Jope 1994). Although the underlying basis for these differences is not known, several differences in the experimental paradigm of Williams and Jope are noteworthy: (1) These authors examined the entire cortex, while we studied two specific areas of cortex, frontal and occipital, where opposite effects of chronic lithium on fos were found; (2) A shorter chronic treatment paradigm and lower dose of lithium was used (4 weeks of $1.7 \mathrm{gm} / \mathrm{kg}$ versus our 7 weeks of 2.19 $\mathrm{gm} / \mathrm{kg}$ ); (3) N-methyl-atropine was also administered along with pilocarpine; (4) The effect of vehicle injection or N-methyl-atropine on fos was not reported. Inasmuch as we examined only one time point after pilocarpine, the regional differences observed may be attributed in part to regional differences in the kinetics of the fos response to pilocarpine. Nonetheless, our studies show that chronic lithium treatment profoundly influ- 
ences muscarinic-initiated changes in fos expression and suggests the possibility that lithium's efficacy in bipolar disorder may involve enhancement as well as inhibition of cholinergic initiated signal transduction.

The modification of cholinergic mediated fos expression by lithium does not appear to be stable, as the effects of pilocarpine normalized in most regions. Whether the enhanced fos expression seen after lithium withdrawal in the frontal cortex reflects an important longerterm effect of lithium or simply a rebound increase due to removal of lithium's influence on factors mediating fos transcription or posttranscriptional effects on fos mRNA stability remains to be established.

Although noradrenergic, serotonergic, and cholinergic mechanisms have been implicated in the action of lithium and in the pathophysiology of mood disorders (Manji et al. 1995 for review), a role for DA is unclear. Dopamine appears to play an inhibitory role in the regulation of fos expression in the striatum (Miller 1990). The ability of haloperidol to induce c-fos in the striatum is complex, but probably involves removal of $D_{2}$ inhibitory control on excitatory neurotransmitters, GABA and on DA, $D_{1}$ receptor-mediated activity (Miller 1990; Guo et al. 1992; Ziolkowska and Hollt 1993; Decker et al. 1995). The enhanced fos expression in the striatum after chronic lithium treatment may reflect further loss of striatal $\mathrm{D}_{2}$-mediated inhibitory control. Evidence to support this derives from a study by Carli et al. (1994) showing that striatal dopaminergic activity is diminished by chronic lithium, possibly through impairment of $\mathrm{G}$ protein coupling to $\mathrm{AC}$. However, changes in PI/ PKC coupling to $D_{1}$ and $D_{2}$ receptors (Di Marzo et al. 1993; Simpson and Morris, 1995), the possibility of significant "cross talk" between the AC/PKA and P/PKC second-messenger systems (Houslay 1991), as well as changes in postreceptor coupling mechanisms of other neurotransmitters also may be considered as additional factors contributing to the enhanced haloperidol-induced fos response elicited by chronic lithium in the striatum and pituitary. The mechanism involved in lithium's inhibitory influence on fos expression after haloperidol in the frontal cortex, occipital cortex, hippocampus, and hypothalamus remains unclear; however, some of the effects may be related to a dampening of fos induction by injection stress, mediated in part, by the dopaminergic system or other systems with which the DA system interacts. The observation that removal of lithium from the diet resulted in fos responses to haloperidol in the frontal cortex, occipital cortex, and hypothalamus similar to that seen in animals fed the normal diet provides some support for this notion. In addition, although levels of fos in the hippocampus after lithium withdrawal and haloperidol were actually higher than in normal diet controls receiving haloperidol, the levels were about the same as those seen in rats fed the normal diet that only received vehicle.
The biological consequences and significance of lithium's chronic effects on fos are not yet known; however, our findings of persistent effects in the frontal cortex and hippocampus are of particular interest because these regions are known to be involved in brain functions regulating mood, level of arousal, and attention. Reduction in basal fos expression in these regions by chronic lithium may alter the threshold for inducible fos that would have an impact on the expression of multiple genes regulated by Fos. Our results reinforce the notion that lithium's complex actions involve multiple neurotransmitter-receptor and postreceptor interactions and that the longer-term behavioral changes believed to be associated with its therapeutic action ultimately require changes in the regulation of neuronal gene expression. Thus the therapeutic effects of lithium cannot be attributable to its initial inhibitory action on PI/PKC signaling but rather to its repeated action at this initial target producing important adaptations that may alter the brain's response to a variety of stimuli, not only at the initial target but also at other interrelated targets. These adaptations may not only involve quantitative changes in signaling but also result in qualitative changes, such as the ability of the brain to respond, for example, to stress. Our observations that chronic lithium administration produces selective effects in the brain on basal fos and may produce differential effects on inducible fos, depending on region and on whether they are mediated by excitatory or inhibitory neural systems, may be relevant to lithium's effectiveness in the treatment of both mania and depression. Identification of the gene products that regulate Fos, that are regulated by Fos, and that are stably affected by chronic lithium may provide a basis for the development of better treatment strategies, a better understanding of the molecular basis of affective disorder, as well as provide new insights into the mechanisms underlying lithium's antimanic and mood-stabilizing action.

\section{ACKNOWLEDGMENTS}

This study was supported by the Swedish Medical Research Council, Grant 10414, Theodor and Vada Stanley Foundation, Karolinska Institute, and Soderstrom-Konigska Foundation/ Swedish Medical Association (AAM). The expert technical assistance of Dr. Carina Stenfors is gratefully acknowledged.

\section{REFERENCES}

Angel P, Karin M (1991): The role of Jun, Fos and AP-1 complexes in cell proliferation and transformation. Biochem Biophys Acta 1072:129-157

Baptista T, Teneud L, Contreras Q, Burguera JL, Hernandez L (1993): Effects of acute and chronic lithium treatment on amphetamine-induced dopamine increase in the nu- 
cleus accumbens and prefrontal cortex in rats as studied by microdialysis. J Neural Transm Gen Sect 94:75-89

Bing G, Filer D, Miller JC, Stone EA (1991): Noradrenergic activation of immediate early genes in rat cerebral cortex. Mol Brain Res 11:43-46

Bunney WE Jr, Garland-Bunney B (1987): Mechanism of action of lithium in affective illness: Basic and clinical applications. In Meltzer HY (ed), Psychopharmacology: The Third Generation of Progress. New York, Raven, pp 553-565

Calabresi P, Pisani A, Mercuri NB, Bernardi G (1993): Lithium treatment blocks long-term synaptic depression in the striatum. Neuron 10:955-962

Carli M, Anand-Srivastava MB, Molina-Holgado E, Dewar KM, Reader TA (1994): Effects of chronic lithium treatments on central dopaminergic receptor systems: $G$ proteins as possible targets. Neurochem Int 24:13-22

Chomcyznski P, Sacchi N (1987): Single-step method of RNA isolation by acid guanidinium thiocyanate-phenol-chloroform extraction. Anal Biochem 162:156-159

Decker KP, Roy-Byrne PP, Merchant KM (1995): Effect of muscimol on haloperidol-induced alteration of neurotensin gene expression in the striatum and nucleus accumbens in the rat. Brain Res 691:9-17

Diehl DJ, Gershon S (1992): The role of dopamine in mood disorders. Comp Psychiatr 33:115-120

Dilsaver SC (1986): Cholinergic mechanisms in depression. Brain Res Rev 11:285-316

Di Marzo V, Vial D, Sokoloff P, Schwartz JC, Piomelli D (1993): Selection of alternative G-mediated signaling pathways at the dopamine $D_{2}$ receptor by protein kinase C. J Neurosci 13:4846-4853

Divish MM, Sheftel G, Boyle A, Kalasapudi VD, Papolos DF, Lachman HM (1991): Differential effect of lithium on fos proto-oncogene expression mediated by receptor and postreceptor activators of protein kinase $C$ and cyclic adenosine monophosphate: Model for its antimanic action. J Neurosci Res 28:40-48

Dragunow M, Robertson GS, Faull RLM, Robertson HA, Janssen $K(1990)$ : $D_{2}$ dopamine receptor antagonists induce Fos and related proteins in rat striatal neurons. Neurosci $37: 287-294$

Duman RS, Heninger GR, Nestler EJ (1994): Molecular psychiatry. Adaptations of receptor-coupled signal transduction pathways underlying stress- and drug-inducted neural plasticity. J Nerv Ment Dis 182:692-700

Ellis J, Lenox RH (1990): Chronic lithium treatment prevents atropine-induced supersensitivity of the muscarinic phosphoinositide response in rat hippocampus. Biol Psychiatr 28:609-619

Franza BR, Rauscher FJ, Josephs SF, Curran T (1988): The Fos complex and Fos-related antigens recognize sequence elements that contain AP-1 binding sites. Science 239: $1150-1153$

Gelenberg AJ, Kane JM, Keller MB, Lavori P, Rosenbaum JF, Cole K, Lavelle J (1989): Comparison of standard and low serum levels of lithium for maintenance treatment of bipolar disorder. N Engl J Med 321:1489-1493

Gilman MZ, Wilson RN, Weinberg RA (1986): Multiple pro- tein-binding sites in the $5^{\prime}$-flanking region regulate fos expression. Mol Cell Biol 6:4305-4316

Glowinski J, Iversen LL (1966): Regional studies of catecholamines in the rat brain: The disposition of $\left[{ }^{3} \mathrm{H}\right]$-norepinephrine, $\left[{ }^{3} \mathrm{H}\right]$-dopamine and $\left[{ }^{3} \mathrm{H}\right]$-dopa in various regions of the brain. J Neurochem 13:655-669

Gottberg E, Montreuil B, Reader T (1988): Acute effects of lithium on dopaminergic responses. Iontophoretic studies in the rat visual cortex. Synapse 2:442-449

Grassi-Zucconi G, Menegazzi M, De Prati AC, Bassetti A, Montagnese P, Mandile P, Cosi C, Bentivoglio M (1993): $c$-fos mRNA is spontaneously induced in the rat brain during the activity period of the circadian cycle. Eur J Neurosci 5:1071-1078

Gubits RM, Smith TM, Fairhurst JL, Yu H (1989): Adrenergic receptors mediate changes in c-fos mRNA levels in brain. Mol Brain Res 6:39-45

Guo N, Robertson GS, Fibiger HC (1992): Scopolamine attenuates haloperidol-induced c-fos expression in the striatum. Brain Res 588:164-167

Houslay MD (1991): "Crosstalk": A pivotal role for proteins kinase $C$ in modulating relationships between signal transduction pathways. Eur J Biochem 195:9-27

Hudson CJ, Young LT, Li PP, Warsh JJ (1993): CNS signal transduction in the pathophysiology and pharmacotherapy of affective disorders and schizophrenia. Synapse 13:278-293

Janowsky DS, Risch SC, Parker D, Huey LY, Judd L (1980): Increased vulnerability to cholinergic stimulation in affective disorder patients. Psychopharmacol Bull 16: 29-31

Kalasapudi VD, Sheftel G, Divish MM, Papolos DF, Lachman HM (1990): Lithium augments fos proto-oncogene expression in PC12 pheochromocytoma cells: Implications for therapeutic action of lithium. Brain Res 521:47-54

Kane JM (1988): The role of neuroleptics in manic-depressive illness. J Clin Psychiatr 49:12-14

Lucibello FC, Ehlert F, Muller R (1991): Multiple interdependent regulatory sites in the mouse c-fos promoter determine basal level transcription: Cell type specific effects. Nucleic Acids Res 19:3583-3591

Manji HK, Lenox RH (1994): Long-term action of lithium: A role for transcriptional and posttranscriptional factors regulated by protein kinase C. Synapse 16:11-28

Manji HK, Potter WZ, Lenox RH (1995): Signal transduction pathways: Molecular targets for lithium's actions. Arch Gen Psychiatr 52:531-543

Manji HK, Bitran JA, Masana MI, Chen G, Hsiao JK, Risby ED, Rudorfer MV, Potter WZ (1991a): Signal transduction modulation by lithium: Cell culture, cerebral microdialysis and human studies. Psychopharmacol Bull 27:199-208

Manji HK, Hsiao JK, Risby ED, Oliver J, Rudorfer MV, Potter MV (1991b): The mechanisms of action of lithium. I. Effects on serotonergic and noradrenergic systems in normal subjects. Arch Gen Psychiatr 48:505-512

Mathé AA, Norstedt Wikner B, Stenfors C, Theodorsson E (1994): Effects of lithium on neuropeptide $Y$, neurokinin $A$ and substance $P$ in brain and peripheral tissues of rat. Lithium 5:241-247

Mathé AA, Miller JC, Stenfors C (1995): Chronic dietary lith- 
ium inhibits basal c-fos mRNA expression in rat brain Prog Neuro-Psychopharmacol Biol Psychiat 19:1177-1187

Meltzer HY, Matsubara S, Lee J-C (1989): Classification of typical and atypical antipsychotic drugs on the basis of $\mathrm{D}-1_{1}, \mathrm{D}_{2}$ and serotonin $\mathrm{pK}_{\mathrm{i}}$ values. J Pharamcol Exp Ther 251:238-246

Miller JC (1990): Induction of c-fos mRNA in rat striatum by neuroleptic drugs. J Neurochem 54:1453-1455

Miller JC, Stone EA, Filer D (1989): Induction of c-fos expression in rat cortex during stress. Soc Neurosci Abst $15: 799$

Morgan JI, Curran T (1991): Stimulus-transcription coupling in the nervous system: Involvement of the inducible protooncogenes fos and jun. Ann Rev Neurosci 14:421

Morinobu S, Nibuya M, Duman RS (1995): Chronic antidepressant treatment down-regulates the induction of $c$-fos mRNA in response to acute stress in frontal cortex. Neuropsychopharmacology 12:221-228

Rauscher FJ III, Sambucetti LC, Curran T, Distel RJ (1988): Common DNA binding site for Fos protein complexes and transcription factor AP-1. Cell 52:471-480

Robertson GS, Fibiger HC (1992): Neuroleptics increase c-Fos expression in the forebrain: Contrasting effects of haloperidol and clozapine. Neurosci 46:315-328

Sassone-Corsi P, Sisson JC, Verma IM (1988): Transcriptional autoregulation of the proto-oncogene fos. Nature 334: 314-319

Schreiber SS, Tocco G, Shors TJ, Thompson RF (1991): Activation of immediate early genes after acute stress. Neuroreport 2:17-20

Seeman P, Lee T, Chau-Wong M, Wong K (1976): Antipsychotic drug doses and neuroleptic/dopamine receptors. Nature 261:717-719

Shaw PE, Frasch S, Nordheim A (1989): Repression of c-fos transcription is mediated through p $6 \gamma^{\mathrm{RF}}$ bound to the SRE. EMBO J 8:2567-2574
Sheng M, Greenberg ME (1990): The regulation and function of $c-f o s$ and other immediate early genes in the nervous system. Neuron 4:477-485

Simpson CF, Morris BJ (1995): Induction of c-fos and zif/268 gene expression in rat striatal neurons, following stimulation of $\mathrm{D}_{1}$-like dopamine receptors, involves protein kinase $\mathrm{A}$ and protein kinase $\mathrm{C}$. Neuroscience 68:97-106

Smeyne RJ, Curran T, Morgan JI (1992): Temporal and spatial expression of a fos-lac $Z$ transgene in the developing nervous system. Mol Brain Res 16:158-162

Swerdlow NR, Koob GF (1987): Dopamine, schizophrenia, mania and depression: Toward a unified hypothesis of cortico-striato-pallido-thalamic function. Behav Brain Sci 10:197-245

Titze-de-Almeida R, Shida H, Guimaraes FS, Del-Bel EA (1994): Stress-induced expression of the c-fos protooncogene in the hippocampal formation. Braz J Med Biol Res 27:1083-1088

Verma IM, Sassone-Corsi (1987): Proto-oncogene fos: complex but versatile regulation. Cell 51:513-514

Weiner ED, Kalasapudi VD, Papolos DF, Lachman HM (1991): Lithium augments pilocarpine-induced fos expression in rat brain. Brain Res 553:117-122

Williams MB, Jope RS (1994): Distinctive rat brain immediate early gene responses to seizures induced by lithium plus pilocarpine. Brain Res Mol Brain Res 25:80-89

Winston SM, Hayward MD, Nestler EJ, Duman RS (1990): Chronic electroconvulsive seizures down-regulate expression of the immediate early genes c-fos and c-jun in rat cerebral cortex. J Neurochim 54:1829-1925

Young LT, Li PP, Kish SJ, Siu KP, Warsh JJ (1991): Postmortem cerebral cortex Gs alpha-subunit levels are elevated in bipolar affective disorder. Brain Res 553:323-326

Ziolkowska B, Hollt V (1993): The NMDA receptor antagonist MK-801 markedly reduces the induction of $c$-fos gene by haloperidol in the mouse striatum. Neurosci Lett 156:39-42 